\title{
Health-related quality of life in patients admitted after a first episode of acute coronary syndrome
}

\author{
Carina Aparecida Marosti Dessotte ${ }^{1}$ \\ Rosana Aparecida Spadoti Dantas² \\ André Schmidt ${ }^{3}$ \\ Lídia Aparecida Rossi ${ }^{4}$
}

This study aimed to investigate health-related quality of life based on the four weeks antecedent to first admission for acute coronary syndrome and describe potential associations between quality of life, gender and prior treatment for any other cardiovascular condition. An exploratory, descriptive and cross-sectional study was conducted in two public hospitals in an inner state city of the State of São Paulo. Of 253 participants studied, $69.2 \%$ were male, $69.6 \%$ were married or living with a partner, and $58.1 \%$ were professionally active before the current hospital admission. Mean age was 57.9 years old. Higher scores were seen in the Social Functioning $(\bar{x}=86.1)$ domain, while the domain perceived as more compromised was Role Physical $(\bar{x}=57.7)$. Female participants and those who had previously been treated for any other cardiovascular condition had lower quality of life, and these differences were all statistically significant $(p<0.05)$.

Descriptors: Quality of Life; Coronary Disease; Acute Coronary Syndrome.

\footnotetext{
${ }^{1}$ RN, Doctoral Student, Escola de Enfermagem de Ribeirão Preto, Universidade de São Paulo, WHO Collaborating Centre for Nursing Research Development, SP, Brazil. E-mail: camarosti@uol.com.br.

${ }^{2}$ RN, Ph.D. in Nursing, Associate Professor, Escola de Enfermagem de Ribeirão Preto, Universidade de São Paulo, WHO Collaborating Centre for Nursing Research Development, SP, Brazil. E-mail: rsdantas@eerp.usp.br.

3 Physician, Ph.D. in Medicine, Professor, Faculdade de Medicina de Ribeirão Preto, Universidade de São Paulo, SP, Brazil. E-mail: aschmidt@fmrp.usp.br.

${ }^{4}$ RN, Ph.D. in Nursing, Full Professor, Escola de Enfermagem de Ribeirão Preto, Universidade de São Paulo, WHO Collaborating Centre for Nursing Research Development, SP, Brazil. E-mail: rizzardo@eerp.usp.br.
}

Corresponding Author:

Rosana Aparecida Spadoti Dantas

Universidade de São Paulo. Escola de Enfermagem de Ribeirão Preto

Departamento de Enfermagem Geral e Especializada

Av. dos Bandeirantes, 3900

Bairro: Monte Alegre

CEP: 14040-902, Ribeirão Preto, SP, Brasi

E-mail: rsdantas@eerp.usp.br 


\section{Qualidade de vida relacionada à saúde de sujeitos internados, decorrente da primeira síndrome coronariana aguda}

O objetivo deste estudo foi investigar a qualidade de vida relacionada à saúde, baseada nas últimas quatro semanas que antecederam a primeira internação, por uma síndrome coronariana aguda, e descrever potenciais associações entre a qualidade de vida, sexo e tratamento prévio para outras doenças cardiovasculares. Usou-se, como método, o estudo descritivo e exploratório, do tipo transversal, realizado em dois hospitais públicos no interior do Estado de São Paulo. Dos 253 sujeitos estudados, 69,2\% eram homens, $69,6 \%$ casados, ou viviam com um parceiro, e $58,1 \%$ eram profissionalmente ativos antes da internação. A idade média era de 57,9 anos. Os maiores escores obtidos foram no domínio aspectos sociais $(\bar{x}=86,1)$, enquanto o domínio mais comprometido foi aspectos físicos $(\bar{x}=57,7)$. Conclui-se que as mulheres, assim como os sujeitos que já faziam tratamento prévio para outras doenças cardiovasculares, apresentaram pior qualidade de vida, e as diferenças foram todas estatisticamente significantes $(p<0,05)$.

Descritores: Qualidade de Vida; Doença das Coronárias; Síndrome Coronariana Aguda.

\section{Calidad de vida relacionada a la salud de sujetos internados, como consecuencia del primer síndrome coronario agudo}

El objetivo de este estudio fue investigar la calidad de vida relacionada a la salud, basada en las últimas cuatro semanas que antecedieron a la primera internación, por un síndrome coronario agudo, y describir potenciales asociaciones entre la calidad de vida, sexo y tratamiento previo para otras enfermedades cardiovasculares. Como método, se utilizó el estudio descriptivo y exploratorio, de tipo transversal, realizado en dos hospitales públicos en el interior del Estado de Sao Paulo. De los 253 sujetos estudiados, $69,2 \%$ eran hombres, $69,6 \%$ casados, o vivían con un compañero, y 58,1\% eran profesionalmente activos antes de la internación. La edad promedio fue de 57,9 años. Los mayores puntajes obtenidos fueron en el dominio aspectos sociales ( $\bar{x}$ $=86,1)$, en cuanto el dominio más comprometido fue aspectos físicos $(x=57,7)$. Se concluye que las mujeres, así como los sujetos que ya hacían tratamiento previo para otras enfermedades cardiovasculares, presentaron peor calidad de vida, y las diferencias fueron todas estadísticamente significativas $(p<0,05)$.

Descriptores: Calidad de Vida; Enfermedad Coronária; Síndrome Coronario Agudo.

\section{Background}

Atherosclerotic cardiovascular diseases are the main causes of death and disability worldwide today. It is estimated that around 81 million U.S. adults have one or more cardiovascular diseases. Myocardial infarction and angina are the most prevalent conditions among men and they increase with age and education ${ }^{(1)}$. The Pan American Health Organization has considered chronic diseases devastating, not only to patients and their families but also to their communities, especially poor ones, and a growing threat to economic development. It is estimated that Latin American and Caribbean countries will experience a threefold increase in the incidence rates of ischemic heart disease and stroke in the next 20 years. In most Latin American and Caribbean countries, chronic diseases are now the main cause of premature mortality and disability, accounting for almost $50 \%$ of disability-adjusted life years lost in the region. It is projected for the first 10 years of the $21^{\text {th }}$ century that cardiovascular diseases will cause around 20.7 million deaths. The projections for the next 20 years include almost a threefold increase in mortality due to ischemic heart disease and stroke in Latin America(2). In Brazil, the specific mortality rate 
(deaths per 100,000) for ischemic disease in individuals aged 40 to 49 is 29, reaching 425 in those aged 70 to 79 years, and 914 in those 80 years or more. Total deaths in absolute numbers due to cardiovascular diseases reported in Brazil in 2005 were 283,565, 84,871 of which were due to ischemic disease(3).

Coronary artery disease (CAD) is the most common cause of acute coronary syndrome (ACS). ACS is characterized mainly by clinical symptoms, such as chest tightness or pain, shortness of breath and fatigue(4). Patients have to face different new life situations after diagnosis, such as having to learn how to live with a heart condition and potential disability for the rest of their life, which has lead to many investigations focusing on these individuals' health-related quality of life (HRQOL).

A comparison of HRQOL between individuals from the general population and those with CAD has shown that the latter have lower scores in both physical and emotional aspects when compared to those without $C A D^{(5-6)}$.

Most studies assessing HRQoL in patients with CAD have been carried out in the United States ${ }^{(6-8)}$, European countries $^{(5,9-10)}$ and a smaller number of studies have been conducted in countries like Canada(11). Their assessments of HRQoL have been largely based on the Medical Outcomes Study: 36-Item Short Form Survey (SF-36) questionnaire and researchers have conducted these assessments at different time points after first hospital admission due to $\operatorname{CAD}^{(7,9-15)}$. However, there are scarce studies using a retrospective approach that assess HRQoL during the first hospital admission, and the few studies available have focused on patients with acute myocardial infarction $(\mathrm{AMI})^{(10)}$. Patients with unstable angina (UA), the other common presentation of ACS, have been barely explored.

Most knowledge on HRQoL in individuals with CAD has been produced in developed countries and predominantly studied patients during rehabilitation after hospital discharge. Bearing in mind the multiplicity of factors involved in the diagnosis and treatment of $C A D$ and the subjective component of quality of life assessment, there is a need to extend this investigation to involve other populations with different sociodemographic and cultural characteristics. People living in developing countries like Brazil may have different perceptions of the domains associated to their HRQoL after being diagnosed with CAD.

Few Brazilian studies have been conducted on HRQoL in CAD patients ${ }^{(15-19)}$. There is a need to explore how these individuals perceive their HRQoL in the month prior to their first hospital admission due to ACS. This knowledge can help health care professionals to better understand how they perceive the manifestations of a diseased heart and, thus, how the health care team should approach them to prevent more severe events and eventually help to develop a care plan during hospital admission and rehabilitation. Based on a literature search and our clinical experience, we decided to explore the following question: are there any differences in HRQoL in patients admitted for the first time due to ACS (AMI and $U A$ ) according to gender and prior treatment for any other cardiovascular condition? Some studies have reported lower scores of HRQoL among women with $\operatorname{CAD}^{(6,8,11,13,16)}$ and other cardiovascular conditions ${ }^{(14)}$.

The objectives of the present study were to investigate HRQoL based on the patients' four weeks of life prior to first hospital admission due to ACS and to describe any potential associations between HRQoL and gender and prior treatment for any other cardiovascular condition.

\section{Methods}

\section{Design, Setting and Sample}

An observational, descriptive, cross-sectional study was conducted in two public hospitals. One of them was the University Hospital, a tertiary care facility affiliated to the School of Medicine of the University of São Paulo, campus of Ribeirão Preto. The University Hospital is considered one of the most advanced public health centers in the country, serving a large population in the metropolitan area around the city, as well as patients from other parts of the state and country. The other hospital was a tertiary care facility too, and had philanthropic purposes (Santa Casa de Misericórdia).

Approval for the study was obtained from the hospitals' Research Ethics Committees. All participants received appropriate verbal and written explanations on the study and both researchers and participants signed an informed consent form.

Potential participants were patients receiving care at the study hospital who met the following inclusion criteria: hospital admission due to a first episode of ACS; admission for at least 24 hours and no more than seven days; age over 21 years old; good clinical (physical and psychological) condition to be able to undergo an interview and participate in the study. In total, 253 participants were included in the study between May 2006 and July 2009. The enrollment period was defined by time and human resources available to conduct the study. No power calculations were performed because 
this study was an observational study, whose primary objective was exploratory and not confirmatory.

\section{Measure}

All data were collected during individual interviews with participants during their admission. The collection instrument comprised sociodemographic (gender, marital status, employment status and date of birth) and clinical (diagnosis of ACS during admission and prior treatment for any other cardiovascular condition) variables. Clinical data were obtained through review of the patient's medical records. Psychoactive drug use during admission was investigated as it can compromise patients' perception of HRQoL.

The HRQoL was assessed using the Medical Outcomes Study (MOS): 36-Item Short Form Survey (SF-36) ${ }^{(20)}$ instrument in a version adapted to Brazilian Portuguese ${ }^{(21)}$, with proven reliability and validity among CAD patients ${ }^{(15-18)}$.

Subjects were asked to consider the last four weeks to answer the questions, which supports the questionnaire's adequacy for the present study. The internal consistency of the items in each SF-36 domain had Cronbach's alpha coefficients ranging from 0.71 (General Health) to 0.97 (Role Emotional and Role Physical), which corresponds to good internal reliability.

\section{Analyses}

Data were processed and analyzed using the
Statistical Package for Social Science (SPSS) version 15.0. To assess potential differences between groups (according to gender and prior treatment), Student's t-test for independent samples was used. A 5\% significance level was set.

\section{Results}

Of 253 participants studied, 175 (69.2\%) were male, $176(69.6 \%)$ were married or living with a partner, and 147 (58.1\%) were professionally active before the current hospital admission due to ACS. Mean age was 57.9 years old (s.d.=12.2), ranging between 25.4 and 82.2 years.

As for diagnosis upon admission, 142 (56.1\%) were admitted due to AMI and 111 (43.9\%) due to UA. It was found that 141 (55.7\%) participants had been treated for any other cardiovascular condition before the first episode of ACS, and the most common associated condition was arterial hypertension (135; $53.0 \%)$. Among all participants, 62 (24.5\%) were taking psychoactive drugs during hospital admission.

The results of the HRQoL assessment in patients first admitted due to ACS are shown in Table 1 . Higher scores were seen in the Social Functioning $(\bar{x}=86.0$; s.d.=26.3) and Role emotion domains ( $x=79.4$; s.d.=39.5), while the domains perceived as more compromised were Role Physical ( $\bar{x}=57.7$; s.d. $=47.6$ ), Mental Health $(\bar{x}=62.9 ;$ s.d. $=25.1)$ and $\operatorname{Vitality}(\bar{x}$ $=63.0 ;$ s.d. $=27.2)$.

Table 1 - Descriptive statistics and reliability of MOS SF-36 subscales ( $n=253$ ). Ribeirão Preto, Brazil, 2006 - 2009

\begin{tabular}{|c|c|c|c|}
\hline MOS SF-36 subscales & Mean (s.d.) & Median (Range) & Cronbach's Alpha* \\
\hline Social Functioning & $86.0(26.3)$ & $100(0-100)$ & 0.90 \\
\hline Role Emotional & $79.4(39.5)$ & $100(0-100)$ & 0.97 \\
\hline Bodily Pain & $71.1(30.5)$ & $72(0-100)$ & 0.91 \\
\hline Physical Functioning & $70.8(32.2)$ & $85(0-100)$ & 0.94 \\
\hline General Health & $67.8(20.0)$ & $72(5-100)$ & 0.71 \\
\hline Vitality & $63.0(27.2)$ & $70(0-100)$ & 0.83 \\
\hline Mental Health & $62.9(25.1)$ & $68(0-100)$ & 0.88 \\
\hline Role Physical & $57.7(47.6)$ & $100(0-100)$ & 0.97 \\
\hline
\end{tabular}

s.d. = standard deviation *According to standardized formula

With respect to psychoactive drug use and HRQoL, higher mean scores were found in the eight SF-36 domains among participants not taking any psychoactive drugs (means ranging between 59.0 in the Role Physical domain and 87.0 in the Social Functioning). Among those taking psychoactive drugs, the most compromised domain was also Role Physical $(\bar{x}=53.6)$ and the least compromised was Social Functioning $(x=82.2)$. However, the difference between the groups studied was only statistically significant for Role Emotional ( $p=0.034)$, Mental Health $(p=0.004)$ and Vitality $(p=0.032)$.

The analysis of potential differences in HRQoL according to prior treatment for any other cardiovascular condition showed that those without prior treatment had significantly higher mean scores in all SF-36 domains (67.1 to 91.5) than those with prior treatment (mean scores ranging between 47.7 and 81.6) (Table 2). 
Table 2 - Means of MOS SF-36 subscales by presence of prior treatment for any other cardiovascular condition and probability values $(p)$ associated to Student's t-test for independent samples. Ribeirão Preto, Brazil, 2006 - 2009

\begin{tabular}{|c|c|c|c|}
\hline \multirow{2}{*}{ MOS SF- 36 subscales } & With prior treatment $(n=141)$ & Without prior treatment $(n=112)$ & \multirow{2}{*}{$p$} \\
\hline & Mean (s.d.) & Mean (s.d.) & \\
\hline Social Functioning & $81.6(29.7)$ & $91.5(20.3)$ & $0.002^{*}$ \\
\hline Role Emotional & $74.2(42.8)$ & $86.0(33.9)$ & $0.015^{*}$ \\
\hline Bodily pain & $66.7(31.4)$ & $76.6(28.4)$ & $0.009^{*}$ \\
\hline General Health & $64.4(20.2)$ & $72.1(19.0)$ & $0.002^{*}$ \\
\hline Physical functioning & $62.2(33.2)$ & $81.8(27.2)$ & $<0.001^{\dagger}$ \\
\hline Mental Health & $59.7(26.3)$ & $67.1(23.1)$ & $0.018^{*}$ \\
\hline Vitality & $57.8(28.3)$ & $69.6(24.3)$ & $<0.001^{\dagger}$ \\
\hline Role Physical & $47.7(48.9)$ & $7.03(42.9)$ & $<0.001^{\dagger}$ \\
\hline
\end{tabular}

$* 0.01<p<0.05 ;{ }^{\dagger} \mathrm{p}<0.01$ : statistically significant

The analysis of HRQoL by gender evidenced that men had higher mean scores ( 89.3 to 65.1 ) than women ( 78.7 to 41.0 ) in all domains, and these differences were statistically significant (Table 3 ).

Table 3 - Means of MOS SF-36 subscales by gender and probability values $(p)$ associated to Student's t-test for independent samples. Ribeirão Preto, Brazil, 2006 2009

\begin{tabular}{lccccc}
\hline \multicolumn{1}{c}{$\begin{array}{c}\text { MoS SF-36 } \\
\text { subscales }\end{array}$} & Male (n=175) & & Female (n=78) & \multirow{2}{c}{$\boldsymbol{p}$} \\
\cline { 2 - 2 } \cline { 5 - 6 } & Mean (s.d.) & & Mean (s.d.) & \\
\hline Social Functioning & $89.3(23.1)$ & & $78.7(31.5)$ & $0.009^{*}$ \\
Role Emotional & $88.2(30.9)$ & & $59.8(48.7)$ & $<0.001^{\dagger}$ \\
Physical Functioning & $78.0(27.7)$ & & $54.8(35.8)$ & $<0.001^{\dagger}$ \\
Bodily Pain & $75.6(28.7)$ & & $61.1(32.1)$ & $<0.001^{\dagger}$ \\
General Health & $70.3(18.4)$ & & $62.2(22.3)$ & $0.006^{*}$ \\
Mental Health & $68.9(21.5)$ & & $46.5(27.4)$ & $<0.001^{\dagger}$ \\
Vitality & $68.8(23.8)$ & & $50.0(29.8)$ & $<0.001^{\dagger}$ \\
Role Physical & $65.1(4.8)$ & & $41.0(47.6)$ & $<0.001^{\dagger}$ \\
\hline
\end{tabular}

$* 0.01<p<0.05 ;{ }^{\dagger} p<0.01$ : statistically significant

\section{Discussion}

The age distribution of our study participants was similar to that reported in other studies investigating patients with $\operatorname{CAD}^{(10,13-16,22)}$. There was a greater proportion of men in our sample, which was also reported in other studies of HRQoL in patients with heart disease ${ }^{(10,12-17,22-23)}$.

With regard to participants' assessment of HRQoL in the SF-36 for the four weeks prior to hospital admission due to a first episode of ACS, lower scores were seen in the Role Physical domain, with an overall mean score of 57.7. This domain assesses how health (physical) problems interfere in their daily activities and work. When this domain was analyzed according to the variables treatment for any other cardiovascular condition, psychoactive drug use during admission and gender, greater compromise was seen among those who had been under treatment ( $x=47.7)$, were taking psychoactive drugs during admission $(x=53.6)$, and females $(\bar{x}=41.0)$. This same impairment was also seen in other studies, but their mean scores were higher than those found in the present study ${ }^{(13-14)}$. However, another Brazilian study on coronary patients reported a mean score of 19 among female patients ${ }^{(16)}$, well below the mean score found in our study.

The highest scores of HRQoL were seen in the Social Functioning domain, with a mean score of 86.0. This domain assesses how (physical or emotional) health problems affect the patients' social activities. The study sample predominantly consisted of low-income patients, a common feature in public hospitals in Brazil. Because they have few opportunities for social life and recreation, these activities usually involve paying family visits and attending church, which do not require much physical exertion.

A comparison of the study results with those of other investigations is limited to a small number of publications that also studied patients with CAD during hospital admission(13-14). However, when the domains with the highest scores before the first hospital admission due to ACS are compared to those found in coronary patients within one year of hospital discharge, the highest scores are still found in the Social Functioning domain( ${ }^{(9,14,16,24)}$.

The lowest scores of HRQoL were seen in the Role Physical domain, which was expected due to limitations caused by CAD. The lowest scores in this domain were also reported in other coronary patients assessed within one year after discharge ${ }^{(12,16,24)}$, though other domains remained compromised as well, such as Vitality(9) and General Health(14).

We expected patients who had been treated for any other cardiovascular condition to have a different perception of HRQoL when compared to those who had 
never been treated, and so compared both groups. The results demonstrated that participants with prior treatment had significantly lower scores in the eight SF36 domains one month prior to their first admission due to ACS. When HRQoL was analyzed by prior treatment, it was verified that the highest mean scores were in the Social Functioning and Role Emotion domains in both groups. However, mean scores were higher among subjects without prior treatment for any other cardiovascular condition. A similar finding was reported in another study, showing lower mean scores among subjects with prior cardiovascular diseases(13).

Potential gender differences in HRQoL were found. Compared to men, women admitted due to a first episode of ACS had statistically lower scores in all SF-36 domains. This finding is corroborated in studies conducted in other countries(10,12-14,22) and in Brazil as well(15-17). Lower HRQoL among women with CAD remained in the assessments after hospital discharge, regardless of their treatment ${ }^{(16,22)}$. These findings suggest that women are more vulnerable, overall have more physical limitations, greater emotional impairment, and suffer more from distress and anxiety than men ${ }^{(25)}$.

In our study, we opted to investigate HRQoL during the four weeks of a patient's life prior to hospital admission, so as to be consistent with the time frame covered in the SF-36 questionnaire. But the assessment of HRQoL during this time period may not have captured the actual variability of health conditions coronary patients experience ${ }^{(18,26)}$.

\section{Implications for clinical practice}

In Brazil, to date, there are no other studies assessing $\mathrm{HRQOL}$ in persons experiencing their first episode of ACS focusing on the month prior to the event. Most Brazilian and international studies have studied coronary patients after hospital discharge while receiving outpatient treatment, during repeat hospitalization and rehabilitation.

A limitation of our study is that our results could not be compared with the general Brazilian population, as there were no studies using SF-36 in the general population. Another limitation is that participants represented only a fraction of patients attending public health settings and that better-off patients attending private clinics and hospitals were not investigated.

The present study was based on a generic HRQoL questionnaire. Further studies using specific questionnaires for this group of patients, e.g. Seattle Angina Questionnaire and MacNew Questionnaire, are needed to produce more knowledge to develop new care protocols for coronary patients, aiming to provide better care and improve their recovery and rehabilitation.

In this sense, the current care model available at coronary units and cardiology wards for treating patients with a first episode of ACS should be reviewed, paying special attention to gender issues, as the present study demonstrated. Based on this information, the multidisciplinary team can develop care plans to minimize physical and emotional impairment of female patients. This can also help to improve their rehabilitation, as some longitudinal studies have demonstrated that their perception of HRQoL tends to get worse over time, i.e. their physical and psychological impairment increases over the years.

\section{Conclusions}

In conclusion, we found an association between HRQoL measured by the eight domains of the SF-36 and prior treatment for any other cardiovascular condition and HRQOL and gender. The patients admitted due to a first episode of ACS already experienced both physical and emotional impairments in several domains of their life. Female participants and those who had been previously treated for any other cardiovascular condition had lower HRQoL.

These study results emphasize the need to individualize care for CAD patients, considering the illness experience and including gender-related aspects. Multidisciplinary teams, composed of psychologists, occupational therapists and nurses for example, could coordinate support groups for these persons. The focus of these groups would be on the persons as a whole, not only on their physical and clinical rehabilitation measures.

Future follow-up research for these patients could reveal whether these differences continue throughout the rehabilitation process.

\section{References}

1. Rosamond W, Flegal K, Furie K, Go A, Greenlund $K$, Haase $N$, et al. Heart disease and stroke statistics - 2008 Update: a report from the American Heart Association Statistics Committee and stroke statistics Subcommittee. Circulation. 2008;117:e25-e146.

2. Pan American Health Organization - World Health Organization. 47th Directing Council-58th session of the regional committee 2006. [acesso $04 \mathrm{dez} 2009$ ]. Disponível em: http://search.bvsalud.org/regional/ resources/pah-a311756. 
3. Indicadores e Dados Básicos - Brasil. Rede Interagencial de Informação para a Saúde. [acesso 04 dez 2009]. Disponível em: http://tabnet.datasus.gov. br/cgi/idb2007/matriz.htm.

4. Anderson JL, Adams CD, Antman EM, Bridges CR, Califf RM, Casey DE, et al. ACC/AHA 2007 Guidelines for the Management of patients with Unstable Angina/ Non-ST Elevation Myocardial Infarction: a Report of the American College of Cardiology/American Heart Association Task Force on Practice Guidelines (Writing Committee of Revise the 2002 Guidelines for the Management of patients with Unstable Angina/NonST Elevation Myocardial Infarction) Developed in Collaboration with the American College of Emergency Physicians, The Society for Cardiovascular Angiography and Interventions, and The Society of Thoracic Surgeons Endorsed by The American Association of Cardiovascular and Pulmonary Rehabilitation and the Society for Academic Emergency Medicine. J Am Coll Cardiol. 2007; 50:e1-e157.

5. Torres MS, Calderón SM, Días IR, Chacón AB, Fernández FL, Martínez IF. Health-related quality of life in coronary heart disease compared to norms in Spanish population. Qual Life Res. 2004;13:1401-7.

6. Ford ES, Mokdad AH, Li C, McGuire LC, Strine TW, Okoro CA, et al. Gender differences in Coronary Heart Disease and Health Related Quality of Life: Findings from 10 States from the 2004 Behavioral Risk Factor Surveillance System. J Womens Health. (Larchmt) 2008;17(5):757-68.

7. Maddox TM, Reid KJ, Rumsfeld JS, Spertus, JA. Oneyear health status outcomes of unstable angina versus myocardial infarction: a prospective, observational cohort study of ACS survivors. BMC Cardiovasc Disord. $2007 ; 7: 28$.

8. Xie J, Wu EQ, Zheng ZJ, Sullivan PW, Zhan L, Labarthe DR. Patient Reported Health Status in Coronary Heart Disease in the United States: Age, Gender, Racial and Ethnic Differences. Circulation. 2008;118:491-7.

9. Kim J, Henderson RA, Pocock SJ, Clayton T, Sculpher MJ, Fox KA. Health-related quality of life after interventional or conservative strategy in patients with unstable angina or non-ST-segment elevation myocardial infarction: one-year results of the third Randomized Intervention Trial of unstable Angina (RITA-3). J Am Coll Cardiol. 2005;45(2):221-8.

10. Bergman E, Malm D, Karlsson JE, Bertero C. Longitudinal study of patients after myocardial infarction: Sense of coherence, quality of life, and symptoms. Heart Lung. 2009;38(2):129-40.
11. Norris CM, Hegadoren K, Pilote L. Depression symptoms have a greater impact on the 1-year health-related quality of life outcomes of women postmyocardial infarction compared to men. Eur J Cardiovasc Nurs. 2007;6(2):92-8.

12. Brink E, Grankvist G, Karlson BW, Hallberg M. Healthrelated quality of life in women and men after acute myocardial infarction. Qual Life Res. 2005;14:749-57.

13. Soto M, Failde I, Márquez S, Benítez E, Ramos I, Barba $A$, et al. Physical and mental component summaries score on the SF-36 in coronary patients. Qual Life Res. 2005;14(3):759-68.

14. Failde II, Soto MM. Changes in Health Related Quality of Life 3 months after an acute coronary syndrome. BMC Public Health. 2006;6:18-28.

15. Gallani MCBJ, Colombo RCR, Alexandre NMC, Bressan-Biajone AM. Qualidade de vida em pacientes coronariopatas. Rev Bras Enferm. 2003;56(1):40-3.

16. Favarato ME, Favarato D, Hueb WA, Aldrighi JM. Qualidade de vida em portadores de doença arterial coronária: comparação entre gêneros. Rev Assoc Med Bras. 2006;52(4):236-41.

17. Favarato ME, Hueb W, Boden WE, Lopes N, Nogueira CRSR, Takiuti $M$, et al. Quality of life in patients with symptomatic multivessel coronary artery disease: A comparative post hoc analyses of medical, angioplasty or surgical strategies-MASS II trial. Int J Cardiol. 2007;116:364-70.

18. Dantas RAS, Ciol MA. Quality of life after Coronary Artery Bypass Surgery. West J Nurs Res. 2008;30(4):477-90.

19. Vila VSC, Rossi LA. Quality of life from the perspective of revascularized patients during rehabilitation: an ethnographic study. Rev. Latino-Am. Enfermagem. janeiro-fevereiro 2008;16(1):7-14.

20. Ware JE, Sherbourne CD. The MOS 36-Item Short Form Health Survey (SF-36): Conceptual Framework and Item Selection. Med Care. 1992;30(6):473-83.

21. Ciconelli RM, Ferraz MB, Santos W, Meinão I, Quaresma MR. Brazilian-Portuguese version of the SF36. A reliable and valid quality of life outcome measure. Rev Bras Reumatol. 1999;39(3):143-50.

22. Emery CF, Frid DJ, Engebretson TO, Alonzo AA, Fish A, Ferketich $A K$, et al. Gender differences in quality of life among cardiac patients. Psychosom Med. 2004;66(2):190-7.

23. Dantas RAS, Gois CLF, Silva LM. Use of the adapted version of the Flanagan Quality of Life Scale with postsurgical cardiac patients. Rev. Latino-Am. Enfermagem. janeiro-fevereiro 2005;13(1):15-20. 
24. Kiebzak GM, Pierson LM, Campbell M, Cook JW. Use of the SF36 general health status survey to document health-related quality of life in patients with coronary artery disease: effect of disease and response to coronary artery bypass graft surgery. Heart Lung. 2002;31(3):207-13.

25. Van-Jaarsveld CH, Sanderman R, Ranchor AV, Ormel J, Van-Veldhuisen DJ, Kempen GI. Gender-specific changes in quality of life following cardiovascular disease: a prospective study. J Clin Epidemiol. 2002;55(11):1105-12.

26. Lindsay GM, Hanlon P, Smith LN, Wheatley DJ. Assessment of changes in general health status using the short-form 36 questionnaire 1 year following coronary artery bypass grafting. Euro J Cardio-thoracic Surg. 2000;18:557-64. 